\title{
ANALYSIS OF CHANGES IN SHELTERBELT LANDSCAPE IN NORTHEAST CHINA
}

\author{
DENG, R. X. ${ }^{1}-$ WANG, W. J. ${ }^{2 *}-$ LI, Y. ${ }^{3}-$ SHI, X. L. ${ }^{4}-$ WeI, Y. C. ${ }^{1}-$ HAO, L. J. ${ }^{1}-$ LI, C. J. ${ }^{1}-$ \\ LIU, W. Y. ${ }^{1}$ \\ ${ }^{1}$ College of Surveying and Geo-informatics, North China University of Water Resources and \\ Electric Power, Zhengzhou 450046, China \\ ${ }^{2}$ College of Resources and Environment, Henan University of Economics and Law, Zhengzhou \\ 450002, China \\ ${ }^{3}$ Northeast Institute of Geography and Agroecology, Chinese Academy of Sciences, Changchun \\ 130102, China \\ ${ }^{4}$ College of Geomatics, Xi'an University of Science and Technology, Xi'an 710054, China \\ *Corresponding author \\ e-mail: wenjuan110@163.com; phone: +86-185-0388-6306 \\ (Received 22 $2^{\text {nd }}$ Apr 2019; accepted $12^{\text {th }}$ Jul 2019)
}

\begin{abstract}
Understanding the shelterbelt development in northeast China over the past 30 years will provide a scientific decision support for its management in future. In this paper, Landsat images were selected to extract shelterbelt information covering three points in time (1990, 2000 and 2010). Shelterbelt density and landscape indexes (ratio of belt to patch, connectivity, and dominance) were introduced to analyze changes in landscape. Farmland landscape indexes (ratio of farmland to zone and fragmentation) were used to analyze the effect of farmland on shelterbelt distribution and change. The result showed that: (1) shelterbelt density had considerable spatial variation. These changes were strong correlated with land-use type. Farmland fragmentation was a main index which significantly affected the connectivity and evenness of shelterbelt, especially on connectivity; (2) shelterbelt density increased about $10 \%$ over the 30 years. This modest increase included two contrasting trends, an increase by $13.2 \%$ from 1990 to 2000 followed by a $2.8 \%$ reduction by 2010 . Even the quantity reduced over 2000-2010, the qualities including connectivity and evenness were getting better overall. The temporal changes of shelterbelt density had little relationship with farmland changes. This research can provide valuable information for decision makers to guide and develop future policies.
\end{abstract}

Keywords: shelterbelt structure, landscape index, geographic information system, remote sensing

\section{Introduction}

In 1978, the Central Committee of the Communist Party of China launched an afforestation project known as the "Three Norths" (or 3N, referring to the North West, the North and the North East of China). The $3 \mathrm{~N}$ is one of China's most important projects at a national level (Moodre and Russell, 1990).

Objectives of the $3 \mathrm{~N}$ project are to control wind and sand erosion, enhance soil and water conservation, improve ecological environments, and produce multiple forest products. This project is acclaimed as China's "green great wall" and "world's best ecological project". Based on an investigation of the State Forestry Administration of China, the $3 \mathrm{~N}$ framework was configured during past 30 years and the ecoenvironmental benefits have begun to appear in wind reduction, soil and water conservation, farmland protection, and sand dune fixation (Wang and Zhou, 2003). 
The Northeast shelterbelt is a part of the $3 \mathrm{~N}$ project. Since the 1980 s, China has invested substantial money and energy into its construction. The construction of ecoeconomic shelterbelts was popular in the late 1980s (Shan et al., 2018). By now, the third phase of $3 \mathrm{~N}$ project has been completed, and the fourth phase is nearing completion. Researching and clarifying the development of the shelterbelt over the past 30 years can help identify problems of this area and provide a scientific decision support for shelterbelt management in the next phase.

Shelterbelts are used to reduce wind speed. They can help to control wind erosion, provide habitat for wildlife, protect crops and homes, and enhance the agricultural landscape (Brandle et al., 2004). The shelterbelts are in a network state on the agricultural landscape, the role of one shelterbelt is like a barrier, which is an important element in the landscape (Ding et al., 1993).

Because of their importance in the agricultural landscape, shelterbelt construction develops very rapidly. The studies were mainly focused on their structure, function and management (Fan et al., 2002). As researches expanding from field scale to landscape scale, geographic information system (GIS) and remote sensing (RS) technologies were widely used in shelterbelt research (Wiseman et al., 2009; Czerepowicz et al., 2012; Deng et al., 2013, 2017; Zheng et al., 2016). Using the principle of the landscape ecology and combining GIS and RS, landscape structure can be analyzed to accurately evaluate development and status at landscape scale. Zhou and Sun (1994) introduced landscape indexes (ratio of belt to patch, connectivity, circuitry, and dominance) to shelterbelt landscape research. These indexes were widely used to evaluate shelterbelt structure at landscape scale (Sun et al., 1997; Li et al., 2003; Guan et al., 2004; Yang et al., 2017). Based on these researches, Shi et al. (2011) developed a method evaluating the spatial heterogeneity of shelterbelts distribution at landscape scale. These researches well measured and evaluated the spatial distribution and heterogeneity in landscape, but they did not analyze the reasons behind these results. Kristensen and Caspersen (2002) analyzed the changes of shelterbelt network density, discussed the farmers' motives for shelterbelt planting in central Jutland. The results of this research provided insight into the driving forces behind shelterbelt planting and removal.

We found that, at landscape scale, the studies were mainly focused on evaluating the spatial distribution, there was few paper existed to study the changes of them, and further to regard the driving forces behind these distributions and changes. Shelterbelts are commonly planted on the farmland in the agricultural landscape. The changes of farmland may be one important factor to affect their changes. Therefore, the purpose of this paper is to research the temporal and spatial dynamics of shelterbelt planting in northeastern China, and analyze how the farmland affects the distributions and changes of them. Therefore, this paper investigates the changes of shelterbelt density and landscape indexes at three points in time (1990, 2000 and 2010). These times were chosen to cover the period of major shifts in shelterbelt planting strategies. The results provide insight into the spatial distribution and temporal changes of shelterbelt density, connectivity and distribution evenness across the study area, and understand the relationship of distributions and changes between shelterbelt and farmland. We suppose this analysis can provide valuable information for decision makers to guide and develop future shelterbelt planting policies. 


\section{Materials and methods}

\section{Study area}

The boundary of northeast shelterbelt protection zone was determined by Three North Shelterbelts Construction Bureau of the State Forestry Administration of China. The area is about $584152 \mathrm{~km}^{2}$. This zone is in eastern Inner Mongolia Autonomous Region and western Northeast China, and embraces Heilongjiang, Jilin and Liaoning provinces. Its extent is $115^{\circ}-130^{\circ} \mathrm{E}$ and $40^{\circ}-50^{\circ} \mathrm{N}$ (Fig. 1). There are very cold and long winter and hot and rainy summer. Agricultural disaster is mainly caused by windstorms and sandstorms, as well as droughts and floods. Winds from the southwest often reach $15-20 \mathrm{~m} / \mathrm{s}$ in spring. Crop types are mainly maize, soybean, millet and sorghum (Zhu et al., 2010).

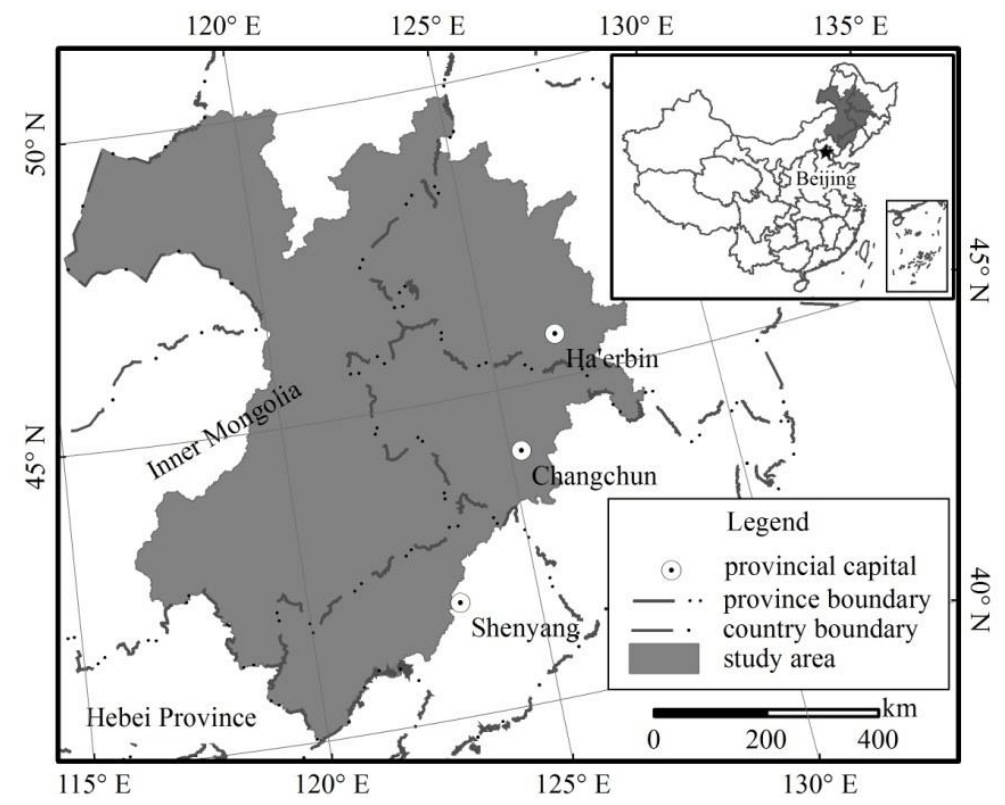

Figure 1. The location of study area

\section{Data source}

\section{Shelterbelt data}

Landsat series images of $30 \mathrm{~m} \times 30 \mathrm{~m}$ spatial resolution were selected to extract shelterbelt information. Specifically, the 1990 images were acquired from Landsat-5 Thematic Mapper (TM) data, the 2000 images from Landsat-5 TM and Landsat-7 Enhanced TM (ETM) data, and the 2010 images from Landsat-5 TM data. For each time, it needed about 48 images to cover the whole study area. In order to accurately extract the information, optimal acquisition dates for images were in May, early and mid-June; second best were in early and mid-October. Considering the atmospheric difference of the images at different times, the atmospheric radiation was made based on each actual condition. Atmospheric radiation and geometric corrections were made for images with ENVI 4.8 software, and the estimated total root mean square error was less than one pixel.

Shelterbelt features in the Landsat images were sufficiently clear because of the moderate resolution and appropriate dates. Vector data were obtained as linear features 
through manual interpretation via a computer interface with ArcMap 10.0 software. The result can be seen in Figure 2. Results were validated by field measurement and accuracy was greater than $95 \%$.
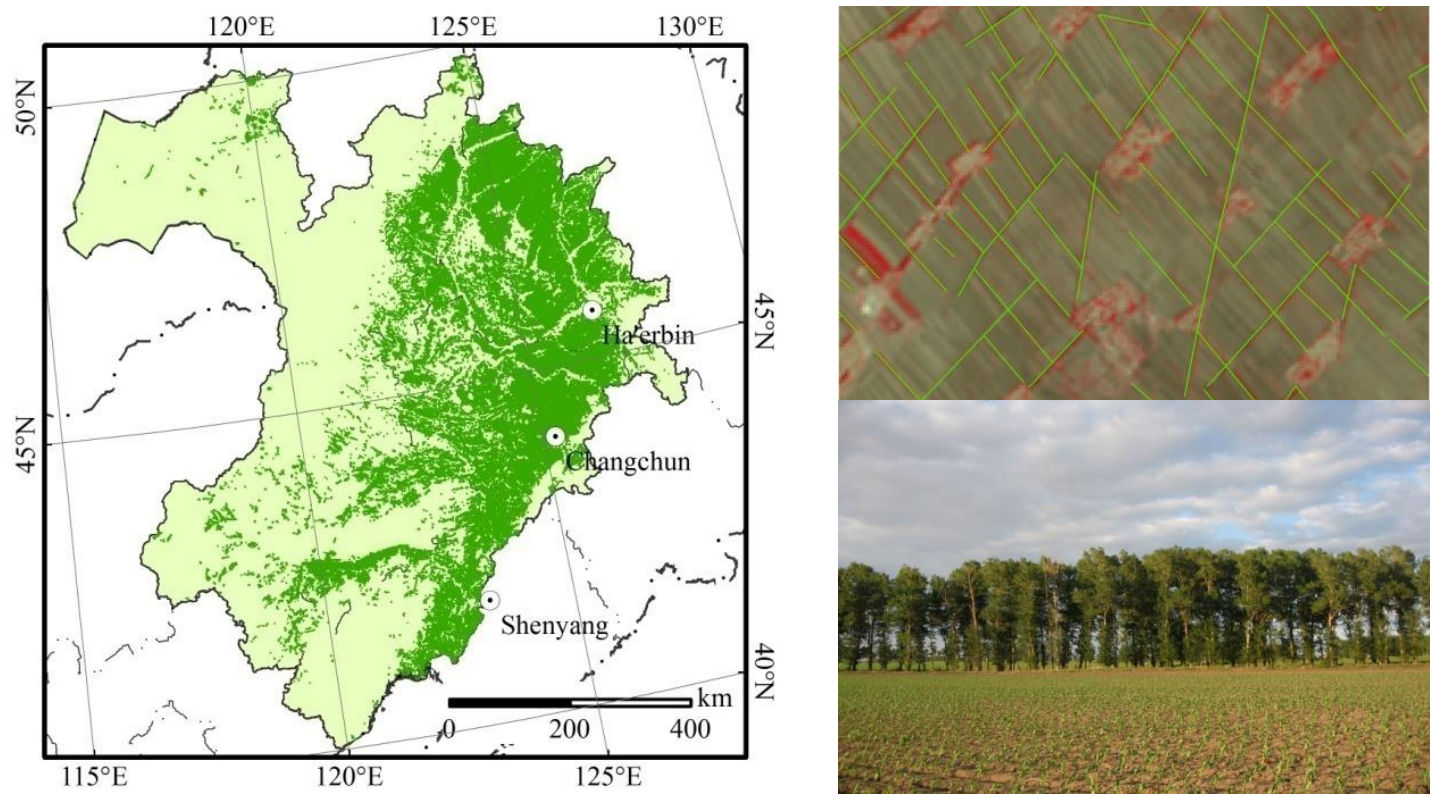

Figure 2. The distribution of the shelterbelts, taken the shelterbelts in 2010 as example. Bottom right: the shelterbelt photographed in field. Top right: the shelterbelt in Landsat image. Left: the extracting result of shelterbelts in 2010

\section{Land use data}

The indicators of land use interpretation were established according to the characteristics of the images, the second Chinese land investigation interpretation standard, expert knowledge, and other related geographic maps. The images were interpreted using the ArcMap 10.0 and the human-computer interactive method. Finally, land uses were classed into six types: farmland, grassland, forest, built-up land, water bodies and marsh. Data accuracy was validated by field surveys: $10 \%$ of the patches were chosen to perform accuracy assessment, the total precision was $90 \%$, the precision of the farmland was more than $95 \%$.

\section{Zoning}

The shelterbelt spatial distribution was related to site conditions. Therefore, we analyzed changes of the objects by the zoning method. Based on regionalization of Chinese agricultural natural resources and consideration of differences in topographic features, air temperature and precipitation, we separated the study area into seven zones. The result is shown in Figure 3 and Table 1.

\section{Landscape index of shelterbelt}

The shelterbelts are in a network state in agricultural fields. Each shelterbelt interconnects and forms a network system. In the system, the junction of two or more belts or the end point of single belt are nodes. The connected edges between nodes are 
belts. Ratio of belt to patch $(P)$, connectivity $(Q)$, and dominance $(D)$ are introduced to estimate the landscape structure at regional scale (Zhou and Sun, 1994; Guan et al., 2004). We calculated these three landscape indexes to describe changes of the network in the study area between 1990 and 2010 .

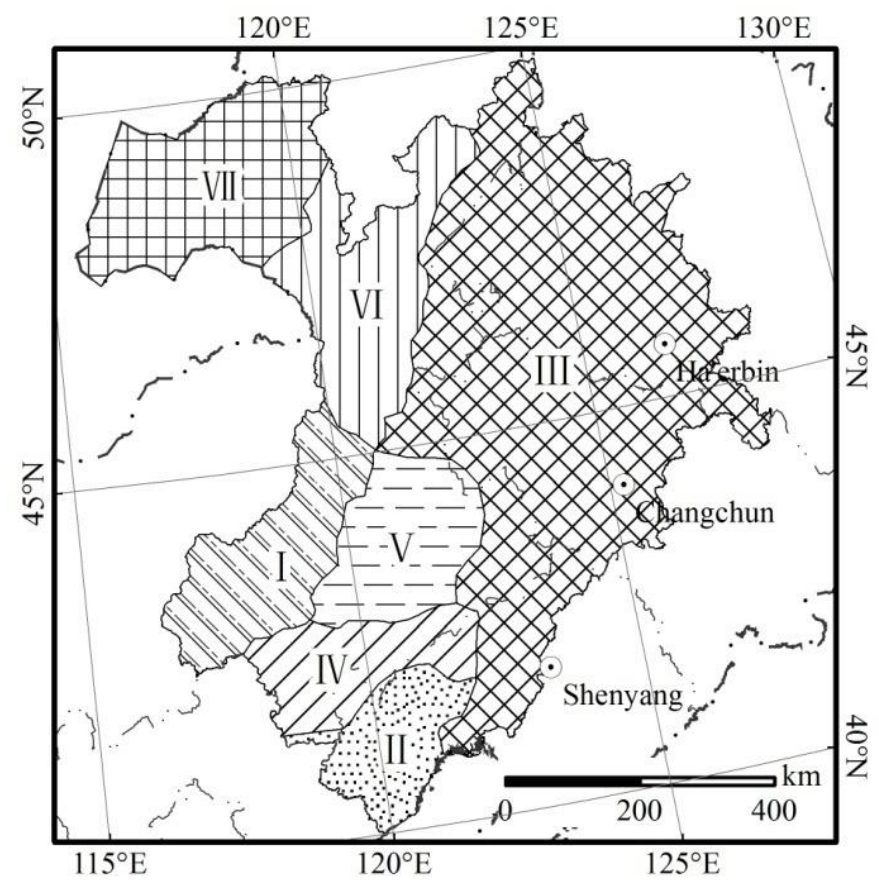

Figure 3. Zones within the study area

Table 1. Description of site conditions in each zone

\begin{tabular}{c|c|c|c|c}
\hline Zone & $\begin{array}{c}\text { Regionalization of agricultural natural } \\
\text { resource }\end{array}$ & Topographic feature & $\begin{array}{c}\text { Temperature } \\
\text { condition }\end{array}$ & $\begin{array}{c}\text { Precipitation } \\
\text { condition }\end{array}$ \\
\hline I & $\begin{array}{c}\text { Pastoral and agricultural region in eastern } \\
\text { Inner Mongolia Plateau }\end{array}$ & $\begin{array}{c}\text { Medium-low } \\
\text { mountain }\end{array}$ & Medium & Semi-arid \\
\hline II & $\begin{array}{c}\text { Agricultural, pastoral and forest region in } \\
\text { Songliao Plain }\end{array}$ & $\begin{array}{c}\text { Medium-low } \\
\text { mountain }\end{array}$ & Warm & Semi-humid \\
\hline III & Agricultural region in Songliao Plain & Flatland & Medium & Semi-humid \\
\hline IV & $\begin{array}{c}\text { Agricultural and pastoral region in eastern } \\
\text { Inner Mongolia Plateau }\end{array}$ & $\begin{array}{c}\text { Medium-low } \\
\text { mountain }\end{array}$ & Medium & Semi-humid \\
\hline V & $\begin{array}{c}\text { Agricultural and pastoral region in eastern } \\
\text { Inner Mongolia Plateau }\end{array}$ & Flatland & Medium & Semi-arid \\
\hline VI & $\begin{array}{c}\text { forest region in eastern Inner Mongolia } \\
\text { Plateau }\end{array}$ & $\begin{array}{c}\text { Medium-low } \\
\text { mountain }\end{array}$ & Medium & Semi-humid \\
\hline VII & $\begin{array}{c}\text { Pastoral region in eastern Inner Mongolia } \\
\text { Plateau }\end{array}$ & Upland plain & Medium & Semi-arid \\
\hline
\end{tabular}

\section{(1) Ratio of belt to patch}

This index is used to describe the abundance extent with aspects of area and number of networks, and measure the number of forest networks. The index is expressed as: 


$$
P=\frac{S_{b}}{A}
$$

where $S_{b}$ is a reasonable area of the shelterbelt networks $\left(\mathrm{km}^{2}\right)$ and $A$ is patch area which should to be protected in this state $\left(\mathrm{km}^{2}\right)$.

\section{(2) Connectivity}

This index is used to measure the formed condition. It is expressed as:

$$
Q=\frac{N_{a}-(n-1)}{L_{M A X}(V)}
$$

where $L_{M A X}(V)$ is the maximum number of belts; $V$ is a reasonable node number; $N_{a}$ is the sum of main and assistant shelterbelts; $n$ is the number of patches that should to be protected.

\section{(3) Dominance of forest network}

This index is used to measure the occupied area, the number and the distribution evenness within the networks. Larger values of this index indicate a larger occupied ratio and vice versa. In other words, a smaller dominance index shows that the number of forest networks is insufficient or that its distribution is not uniform. The index is expressed as

$$
D=\frac{1}{2} \cdot\left(\frac{R_{d}+R_{f}}{2}+R_{c}\right)
$$

where $R_{d}$ represents relative abundance in the network, $R_{f}$ represents frequency in the network, and $R_{c}$ represents coverage in the network.

\section{Landscape index of farmland}

The farmland area was extracted from land use data by GIS method. Ratio of farmland to zone $(P F)$ and fragmentation $(C F)$ are chosen to estimate the landscape structure of farmland in this paper. We calculated these two landscape indexes to describe distributions and changes of the farmland in the study area between 1990 and 2010 .

\section{(1) Ratio of farmland to zone}

This index is used to describe the quantity or density of farmland in the zone, which is expressed as

$$
P F=\frac{S_{f}}{S}
$$

where $S_{f}$ is the area of farmland in the zone, and $S$ is the area of zone that farmland located in. 


\section{(2) Fragmentation of farmland}

This index is used to describe the degree of farmland fragmentation in the zone, which is expressed as

$$
C F=\frac{N}{S_{f}}
$$

where $N$ is the number of farmland patches in the zone.

\section{Results and discussion}

\section{Spatial distribution of shelterbelt density and landscape indexes}

Shelterbelt density, expressed as shelterbelt length divided by zone area, is used to analyze spatial distribution in the study area. The results indicated that the spatial distribution at each time was similar, but shelterbelt density varied considerably by zone (Fig. 4).

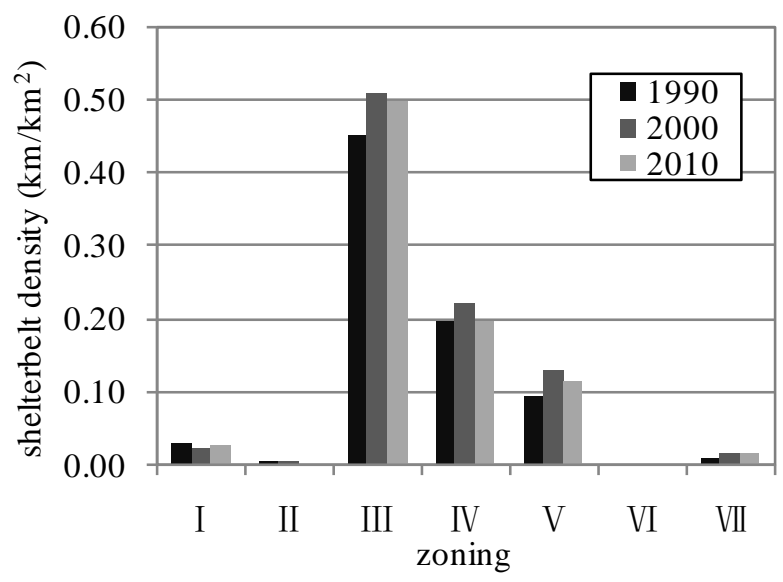

Figure 4. Shelterbelt density in each zone

Comparing shelterbelt density with site conditions in each zone, we found strong correlation between density and land-use type in the study area. The greatest shelterbelt density was in zone III, an agricultural region, it also had the largest area and the most shelterbelt length than other area. This was followed by zones IV and V, which were agricultural and pastoral regions. Then came zone I and VII, a pastoral or pastoral and agricultural region. Finally, with the smallest shelterbelt densities, zones II and VI, both were forest regions. We conclude that shelterbelt density decreased as land-use type transferred from agriculture to pastoral and then forest. This result is related to the shelterbelt protection function. That is, the main role of shelterbelt is to protect homes, crops and livestock by reducing wind speed, and the main land-use type is agriculture across the study area. In forest regions, windstorms and sandstorms are less frequent than the other regions, and lower shelterbelt densities there are reasonable.

Figure 5 showed the distribution of changes in landscape index between 1990 and 2010. Landscape distributions were similar in zones III, IV and V. We can see that $P$ 
and $D$ values in III were obvious higher than other zones, the seconds were IV and V, but $Q$ was almost equal to IV and $\mathrm{V}$, although it was still larger than other zones. The result indicated that, the numbers of shelterbelt were larger, the shelterbelt connectivity were better, and the shelterbelt distributions were more uniform in these three zones.

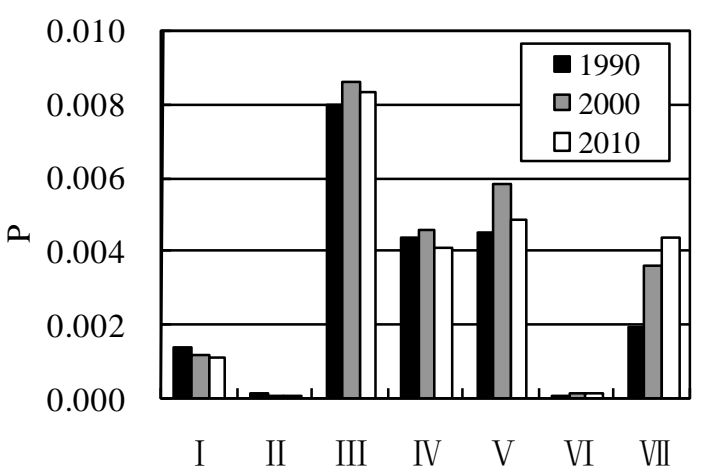

(a)

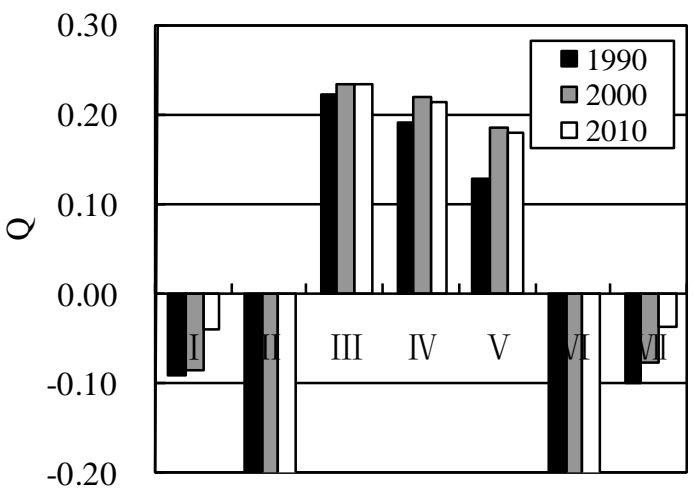

(b)

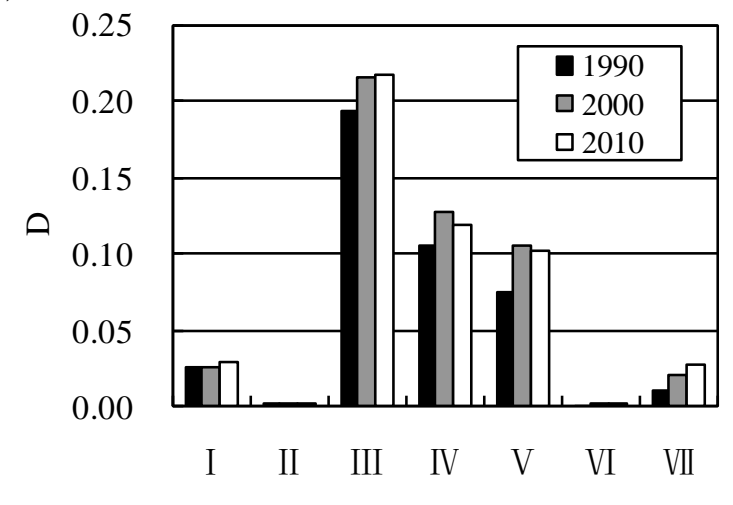

(c)

Figure 5. The landscape indexes in each zone

Compared with Figures 4 and $5 a$, they showed that $P$ values in I and VII were higher than shelterbelt density in these zones. But they were still lower than III, IV and V. the reason for the lower landscape indexes in I, II, VI and VII was that forest or pastoral land was the dominant land-use type. Moreover, cropland was scattered in these zones, so shelterbelts in such land were fragmented.

\section{Relationship of landscape indexes between shelterbelt and farmland}

Shelterbelts are generally planted in the farmland, which may affect the shelterbelt landscape index. $P F$ and $C F$ were chosen as farmland indexes to analyze their relation with shelterbelt indexes. By calculating the mean value of each index in each zone, the relationship between landscape indexes of shelterbelt and $P F$ showed in Figure 6. We can see that, the farmland density mainly affected the shelterbelt evenness (the coefficient of determination $\left(\mathrm{R}^{2}\right)$ was 0.638 between $D$ and $P F$ ). The relationship between farmland density and shelterbelt number was not as obvious as we thought $\left(\mathrm{R}^{2}\right.$ was 0.364 between $P$ and $P F$ ). By analyzed these two indexes in each zone, we found that two zones had opposite trend: in zone II, the $P F$ value was high, which was the third one for all zones. But $P$ value in this zone was the last. That because this zone 
belonged to the agriculture, pastoral and forest transitional region, where land use type was more fragmental. Farmland fragmentation was a main factor to affect the $P$ in this zone; the other was in zone VII, which had the smallest farmland density, the $P$ value was up to the forth for all zone. This zone belonged to pastoral region and upland plain, where was more frequently affected by wind damage. For this reason, it may result that the shelterbelt spacing distance was closer than other areas. If we discarded these two zones, the relationship between these two indexes was increased to 0.775 . Therefore, farmland density had some influences on shelterbelt number, but the main reason may be farmland fragmentation or site conditions.

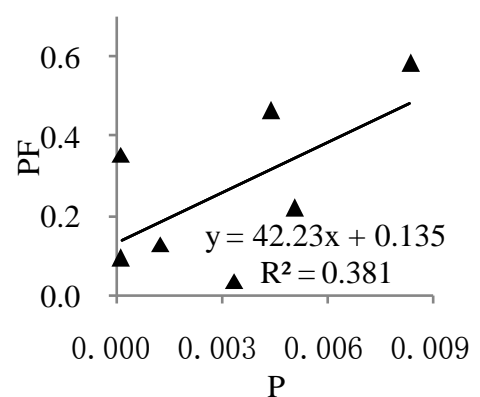

$\mathrm{P}$

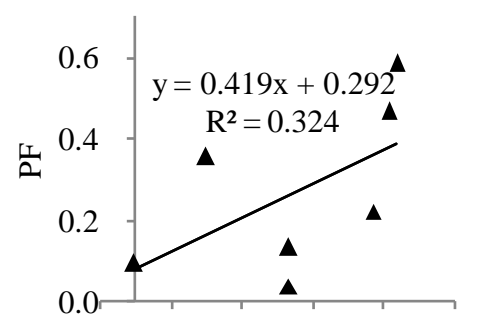

$-0.6-0.4-0.2 \underset{Q}{0} 0.0 .20 .4$

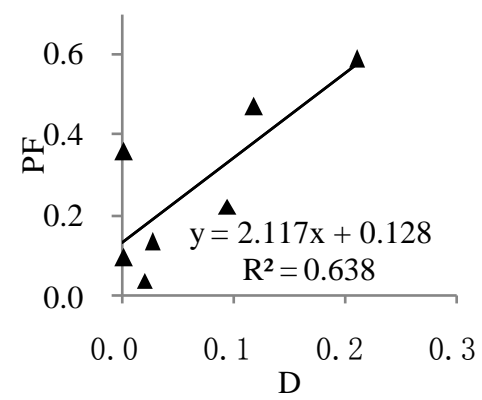

Figure 6. The relationships between landscape indexes of shelterbelt and PF

The relationship between landscape indexes of shelterbelt and $C F$ showed in Figure 7. We can see that, $\mathrm{R}^{2}$ was 0.568 between $P$ and $C F$, which indicated that farmland fragmentation could affect the shelterbelt number. $\mathrm{R}^{2}$ was 0.773 between $Q$ and $C F$, and was 0.679 between $D$ and $C F$, which indicated that farmland fragmentation could significantly affect the connectivity and evenness of shelterbelt, especially on connectivity. The result revealed that farmland fragmentation was a main index to affect the landscape pattern of shelterbelt. The lower of the farmland fragmentation, the higher connectivity and evenness of shelterbelt, and that may cause larger shelterbelt numbers.

\section{Temporal change of shelterbelts density}

Shelterbelt density increased by about $10 \%$ in the last 30 years, revealing that the number of shelterbelts were relatively stable over this period. The modest increase included two contrasting trends during the period: an increase by 13.2\% from 1990 to 2000 followed by a $2.8 \%$ reduction by 2010 . As a result of these changes, the density increased from $0.238 \mathrm{~km} / \mathrm{km}^{2}$ around 1990 to $0.269 \mathrm{~km} / \mathrm{km}^{2}$ around 2000 . This then decreased to $0.262 \mathrm{~km} / \mathrm{km}^{2}$ around 2010. The changes of the density between 1990 and 2000, and between 2000 and 2010 can be seen from Table 2, the value was calculated 
by shelterbelt lengths divided into total lengths in each zone. Such changes of the density were closely related to the $3 \mathrm{~N}$ project. The first phase of this project was from 1978 to 1985 . One of the main objectives in this phase was to plant more trees. The second phase from 1986 to 1996 aimed at strengthening gains made during the first phase (Moodre and Russell, 2003). For this reason, the shelterbelt density increased between 1990 and 2000. After 2000, many shelterbelts developed into over-mature forests and, because of destruction by humans, plant disease and insect pests, many shelterbelts were lost and the construction of the agro-forestry system entered updating phase. In this phase, many shelterbelts were updated, and sometimes they were too young to be recognized by remote sensing. Therefore, the density decreased between 2000 and 2010.

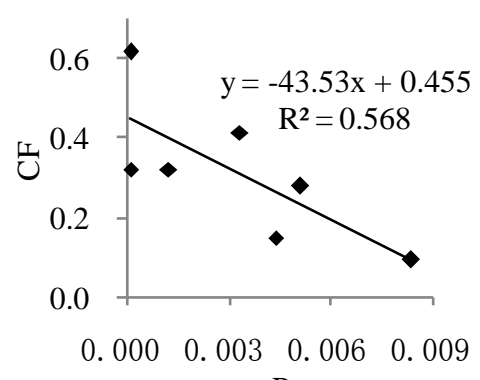

$\mathrm{P}$

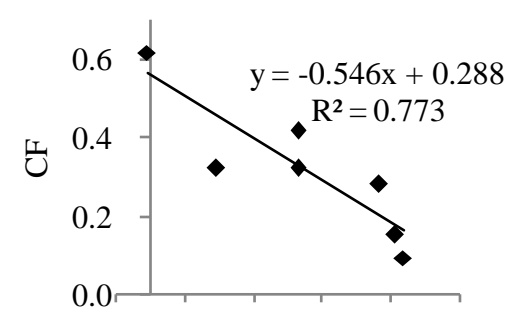

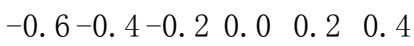

$\mathrm{Q}$

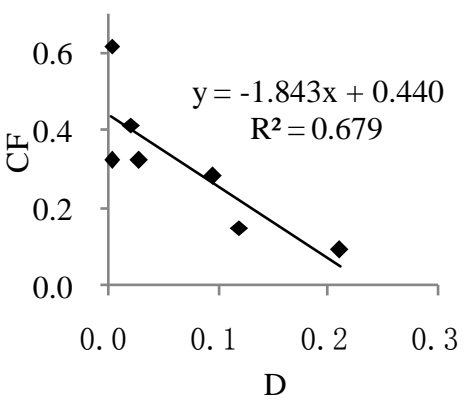

Figure 7. The relationships between landscape indexes of shelterbelt and CF

Table 2. Shelterbelt changes from 1990 to 2000 and from 2000 to 2010

\begin{tabular}{c|c|c|c|c|c|c}
\hline \multirow{2}{*}{ Zone } & \multicolumn{3}{|c|}{ Changes between 1990 and 2000 } & \multicolumn{3}{|c}{ Changes between 2000 and 2010 } \\
\cline { 2 - 7 } & Added (\%) & Reduced (\%) & Added in total (\%) & Added (\%) & Reduced (\%) & Added in total (\%) \\
\hline I & 28.7 & 52.4 & -23.7 & 49.7 & 30.7 & 19.0 \\
II & 27.7 & 70.3 & -42.6 & 20.4 & 39.3 & -18.9 \\
III & 24.1 & 11.6 & 12.5 & 14.8 & 17.1 & -2.3 \\
IV & 39.7 & 27.1 & 12.6 & 9.7 & 21.0 & -11.3 \\
V & 48.8 & 10.6 & 38.2 & 12.5 & 23.5 & -11.0 \\
VI & 50.6 & 18.9 & 31.7 & 63.3 & 44.2 & 19.1 \\
VII & 140.9 & 53.9 & 87.0 & 30.7 & 13.2 & 17.5 \\
Average & 26.3 & 13.1 & 13.2 & 14.8 & 17.7 & -2.8 \\
\hline
\end{tabular}

Added means new planted shelterbelts during this period; reduced means disappeared shelterbelts during this period; added in total means added minus reduced shelterbelts, "_" means reduced in total. The average value of the last row is calculated by changed divided total shelterbelts, not the average value of the seven zones 
From Table 2, we can also find that between 1990 and 2000, the percent of the new planted shelterbelts was $26.3 \%$, the fastest increased area was zone VII. The first reason was the shelterbelt density in 1990 was low in this area, and the second reason was that more shelterbelts were planted compared to the past time of this area. But we also seen that the reduced percent in VII was more faster, only second to II, the third was I. These three zones reduced faster than other areas obviously, which may be related to the site conditions. Between 2000 and 2010, the percent of new planted shelterbelts was lower than the first phase, but the disappeared shelterbelts more higher. The higher percent of added shelterbelts were in I, VI and VII, these areas were mostly belonged to pastoral or forest region. This means that the shelterbelt construction had been strengthened in these areas. Instead, Zones III, IV and V, had better shelterbelt density, the added percent was totally reduced, the shelterbelts needed to be timely updated in these areas.

The change of farmland area was produced by overlapping method. The result can be used to analyze the relationship between the changes of shelterbelt density and farmland. If the new planted shelterbelts were in the new added farmland, we considered the added shelterbelts were related to farmland, if not, there were other reasons. The same as the reduced shelterbelts. The results were shown in Figures 8 and 9.
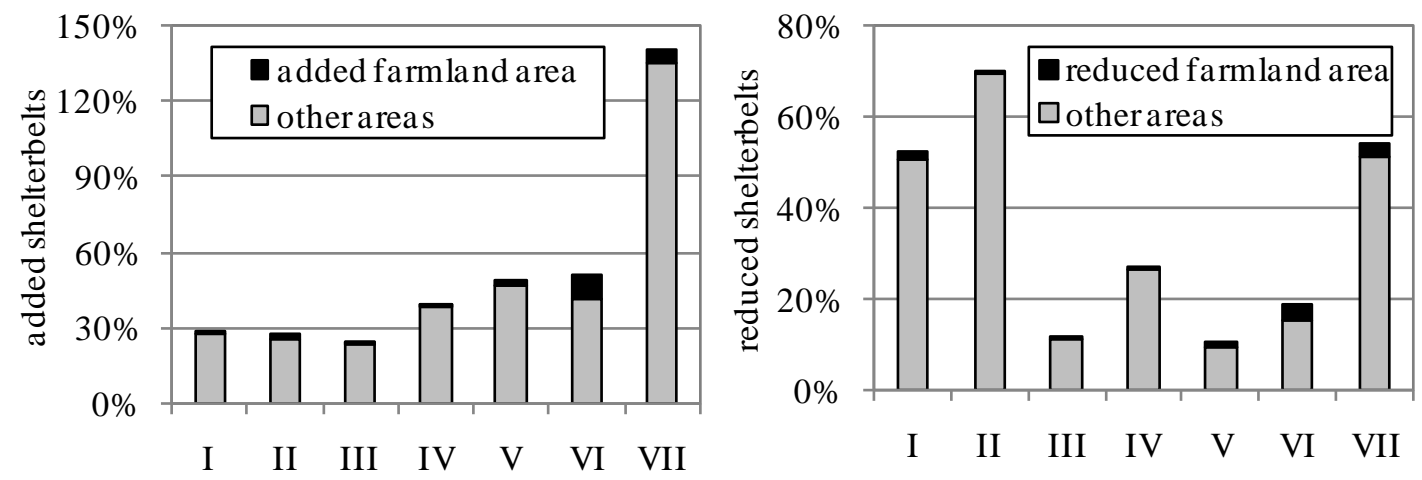

Figure 8. The comparison between the changes of shelterbelt density and farmland from 1990 to 2000
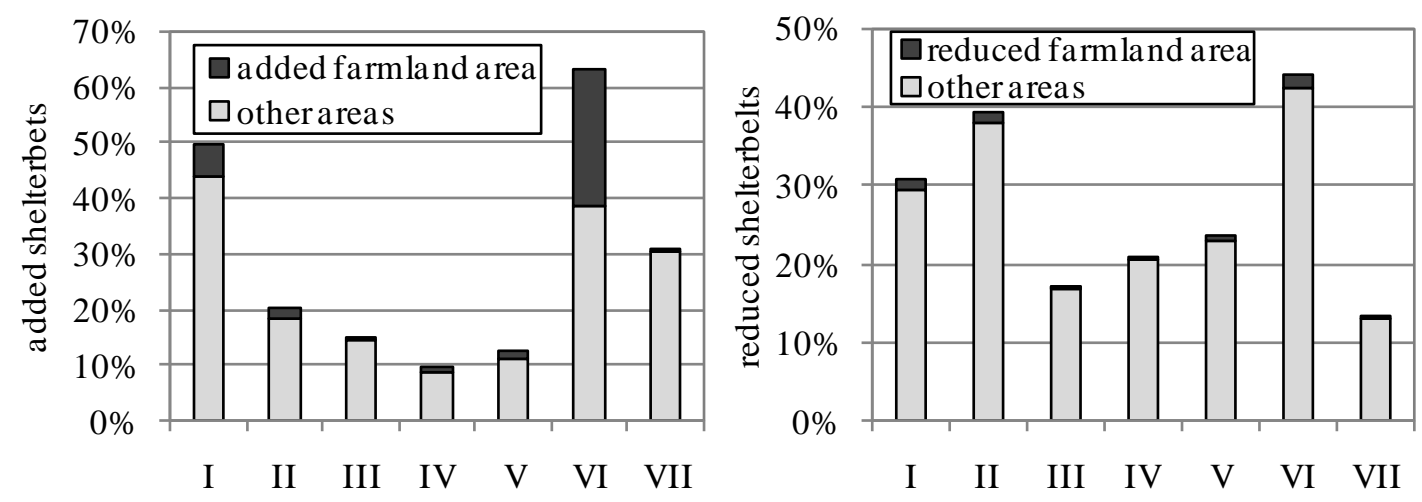

Figure 9. The comparison between the changes of shelterbelt density and farmland from 2000 to 2010 
Figure 8 showed that the changes of shelterbelts density had little relationship with farmland changes. The new planted percent was $26.3 \%$ between 1990 and 2000, only $0.9 \%$ of them were added in new added farmlands, the other $99.1 \%$ were added by other reasons. The reduced percent was $13.1 \%$ between 1990 and 2000, only $1.6 \%$ of them were reduced in reduced farmlands, the other $98.4 \%$ were reduced by other reasons. The similar results appeared between 2000 and 2010 (seen in Fig. 9), the added shelterbelts in new added farmlands were $2.5 \%$ for total added shelterbelts, and the reduced were $0.7 \%$. We can conclude that the farmland changes were not the main factor to affect the changes of shelterbelt densities. The added shelterbelts were mainly related to the shelterbelt construction by managers. The reduced shelterbelts may be mainly caused by site conditions, or human destruction, which we did not discuss in this paper, and will be done in the future work.

\section{Change analysis of landscape indexes of shelterbelt}

The changes of landscape indexes of shelterbelt and farmland between 1990 and 2010 can be seen in Table 3. It indicated that between 1990 and 2010, the landscape indexes were increased totally. Although the $P$ value reduced from 2000 to 2010, the change was not obvious. The most important was, the $Q$ and $D$ were more and more better during this period, which means that, even the quantity of the shelterbelt reduced between 2000 and 2010, the qualities including connectivity and distribution evenness were more better. This means that, after decades of construction, the landscape pattern of shelterbelt had been improved. But compared to the optimized network, it had many more harder works to do.

Table 3. The landscape index changes of shelterbelt and farmland between 1990 and 2010

\begin{tabular}{c|c|c|c|c|c|c|c}
\hline & Shelterbelt & $\boldsymbol{P}$ & $\boldsymbol{Q}$ & $\boldsymbol{D}$ & Farmland & $\boldsymbol{P F}$ & $\boldsymbol{C F}$ \\
\hline 1990 & & 0.0066 & 0.205 & 0.136 & & 0.358 & 0.192 \\
2000 & & 0.0071 & 0.223 & 0.159 & & 0.375 & 0.129 \\
2010 & & 0.0068 & 0.224 & 0.160 & & 0.381 & 0.118 \\
\hline
\end{tabular}

Table 3 also showed that the landscape indexes of farmland were more and more better. Farmland area was increased, and fragmentation was reduced. In order to understand the relationship of landscape indexes between shelterbelt and farmland, we calculated the changed of each index from 1990 to 2000 and from 2000 to 2010 in each zone respectively, and then analyzed the relationship of the landscape index changes between shelterbelt and farmland. The result showed that, there was no significant relationship between landscape index changes of shelterbelt and farmland during these periods.

\section{Conclusion}

The following conclusions are drawn from the analysis.

Shelterbelt densities varied considerably by zone. There is a close correlation between shelterbelt density and land-use type in the study area, with that density decreasing as the type transitioned from agriculture to pastoral and then forest. 
Distributions of shelterbelt in landscape index between 1990 and 2010 showed two opposing trends in seven zones. The reason for these results appeared closely connected to land-use type. Farmland fragmentation was a main index which had significantly effect on the connectivity and evenness of shelterbelt, especially on connectivity. Farmland density mainly affected the shelterbelt evenness. The shelterbelt numbers were affected by many factors, including farmland density, fragmentation and site conditions.

Shelterbelt density increased by about $10 \%$ over the last 30 years. After decades years of construction, the landscape pattern of shelterbelt had been improved. These changes of shelterbelt density had little relationship with farmland changes. The added shelterbelts were mainly related to the construction by managers. The reduced shelterbelts may be mainly caused by site conditions, or human destruction.

During the research, we found that the distribution and change shelterbelts were also closed related with the site conditions, like soil type, elevation, temperature and precipitation, which we did not discuss in this paper. In the future work, we will study the effect of site conditions on the changes of shelterbelt.

Acknowledgements. This work was supported by the National Natural Science Foundation of China under Grant number 31971723; the Key Technologies Research and Development Program of Henan Province under Grant number 192102110122.

\section{REFERENCES}

[1] Brandle, J. R., Hodges, L., Zhou, X. H. (2004): Windbreaks in North American agricultural systems. - Agrofor. Syst. 61: 65-78.

[2] Czerepowicz, L., Case, B. S., Doscher, C. (2012): Using satellite image data to estimate aboveground shelterbelt carbon stocks across an agricultural landscape. - Agric. Ecosyst. Environ. 156: 142-150.

[3] Deng, R. X., Li, Y., Wang, W. J., Zhang, S. W. (2013): Recognition of shelterbelt continuity using remote sensing and waveform recognition. - Agrofor. Syst. 87: 827-834.

[4] Deng, R. X., Li, Y., Xu, X. L., Wang, W. J., Wei, Y. C.(2017): Remote estimation of shelterbelt width from SPOT5 imagery. - Agrofor. Syst. 91: 161-172.

[5] Ding, Y. X., Jiang, S. R., Luan, Y. L., Hu, Y. Q., Cai, F. (1993): Landscape ecological analyses on the special structure of shelterbelt. - J. Nanjing For. Univ. 17(2): 7-12.

[6] Fan, Z. P., Zeng, D. H., Zhu, J. J., Jiang, F. Q., Yu, X. X. (2002): Advance in characteristics of ecological effects of farmland shelterbelts. - J. Soil Water Conserv. 16(4): 130-133.

[7] Guan, W. B., Li, C. P., Fang, X. Z. Zhao, T. N., Chen, J. G., Sun, B. P. (2004): Evaluation of landscape ecology of shelterbelt system of Beizang Town, Daxing County, Beijing. - J. Beijing For. Univ. 26(2): 25-30.

[8] Kristensen, S. P., Caspersen, O. H. (2002): Analysis of changes in a shelterbelt network landscape in central Jutland, Denmark. - J. Environ. Manage. 66: 171-183.

[9] Li, C. P., Guan, W. B., Fan, X. Z., Zhao, T. N., Chen, J. G., Sun, B. P. (2003): Assessment of landscape ecology of agricultural protection forestsystem at Beizang Town, Daxing County, Beijing. - J. For. Res. 14(2), 135-140.

[10] Moodre, R., Russell, R.(1990): The 'Three Norths' forest protection system - China. Agrofor. Syst.10: 71-88.

[11] Shan, Q. H., Zhang, J. F., Sun, S. Y., Chen, G. C., Zhang, H. D., Shen, L. M.(2018): Construction of coastline shelterbelts and assessment of their environmental effects in Yuyao, China. - Land Degrad. Dev. 29(8): 2428-2437. 
[12] Shi, X. L., Li, Y., Deng, R. X. (2011): A method for spatial heterogeneity evaluation on landscape pattern of farmland shelterbelt networks: A case study in midwest of Jilin province, China. - Chin. Geogr. Sci. 21(1): 48-56.

[13] Sun, B. P., Yue, D. P., Zhao, T. P., Cheng, T. R. (1997): The Evaluation of the spatial landscape pattern of farmland shelterbelt networks in BeizangTown, Daxing County, Beijing. - J. Beijing For. Univ. 19(1): 45-50.

[14] Wang, H. J., Zhou, H.(2003): A simulation study on the eco-environmental effects of 3N Shelterbelt in North China. - Glob. Planet. Change 37: 231-246.

[15] Wiseman, G., Kortb, J., Walker, D. (2009): Quantification of shelterbelt characteristics using high-resolution imagery. - Agric. Ecosyst. Environ. 131: 111-117.

[16] Yang, S. Y., Yang, H. J., Liu, L. J., Li, X. Y. (2017): Evaluating the landscape pattern of the farmland windbreaks in the Manas River Basin oasis. - Chin. J. Ecol. 36(6): 16901698.

[17] Zheng, X., Zhu, J. J., Xing, Z. F. (2016): Assessment of the effects of shelterbelts on crop yields at the regional scale in Northeast China. - Agric. Syst. 143: 49-60.

[18] Zhou, X. H., Sun, Z. W.(1994): On measuring and evaluating the spatial pattern of shelterbelt networks in landscape. - Acta Ecol. Sin. 14(1): 24-31.

[19] Zhu, J. Z., He, K. N., Wei, T. X. (2010): Science of Farmland Shelterbelt. 2nd Ed. Chinese Forestry Press, Beijing, pp. 45-46. 